\title{
Institutional biosafety committees and public participation: assessing an experiment
}

\author{
Diana B. Dutton* \& John L. Hochheimer ${ }^{\dagger}$
}

THE regulation of recombinant DNA research has evolved at a pace almost as dizzying as that of the research itself. Only seven years ago, the scientific community voluntarily halted certain experiments while potential hazards were investigated.In 1976, the National Institutes of Health (NIH) issued regulatory guidelines mandating specific methods of physical and biological containment, and prohibiting high-risk experiments. Since then, regulatory controls have been steadily relaxed in light of evidence that risks may be less than initially feared. But some experiments are still considered potentially hazardous, and disagreement persists about whether the research poses long-term or low level risks ${ }^{1-3}$

Another major trend has been regulatory decentralization. In 1978, revised guidelines shifted primary authority for enforcement from NIH to locally-appointed institutional biosafety committees in order to simplify administrative procedures and to encourage local responsibility, although NIH continued to monitor committee decisions $^{4}$.

\section{Effects of NIH guidelines}

Since 1978, the authority of biosafety committees has expanded to the point where virtually no federal oversight remains. Greater discretion has also been delegated to individual researchers; less than 15 per cent of permitted experiments now require prior approval from the biosafety committee. Retrospective review enables the committees to monitor safety standards without impeding most experiments. A recent report by the Congressional Office of Technology Assessment calls the guidelines "a comprehensive, flexible, and nonburdensome way of dealing with the physical risks associated with recombinant DNA research while permitting the work to go forward"'.

The 1978 guidelines also instituted significant changes in public participation in decision-making. NIH's Recombinant DNA Advisory Committee was broadened to include more individuals from fields outside the biomedical sciences, each biosafety committee was required to include at least two members not affiliated

*Department of Family, Community and Preventive Medicine, School of Medicine, Stanford University, and I Institute for Communication Research, Stanford University, Stanford, California 94305, USA.

with the institution (often called "public" members) to represent community interests. Further, biosafety committees were required to make the minutes of their meetings available to the public upon request and were "encouraged" to hold public meetings whenever possible.

These provisions were adopted in response to charges by public interest groups and others that decision-making had been dominated by scientists and technical experts ${ }^{5,6}$. They evoked sharply

role, biosafety committees have never been systematically evaluated. Previous plans announced by NIH for a two-year national study met strenuous opposition from biosafety committee chairpersons ${ }^{12}$ and have not been pursued.

The regulation of recombinant DNA research symbolizes, to many, the way that society will deal with scientific and technological innovations involving potential risks. For such issues, as Court of Appeals Judge David Bazelon has noted,

The most innovative aspect of institutional biosafety committees, responsible in the United States for local oversight of recombinant DNA research, is mandatory participation from outside the institution. A survey of Californian committees and selected national data reveals wide variability in committee structure and procedures. Public participation, although constrained in various ways, has been generally constructive.

divergent reactions. Many scientists were openly sceptical about the public's involvement in complex technical issues ${ }^{7,8}$. Some warned - recalling Lysenkoism that it could lead to political repression?. Others saw a greater danger in the widening rift between science and society, and looked to increased public involvement in science to heal this rift ${ }^{10}$. The 1978 guidelines clearly struck a compromise between the basic changes proposed by critics $^{11}$ and the pleas of scientists to "quietly dismantle the whole hateful (regulatory) artifice" (ref. 7). Yet, these provisions did offer the possibility of a direct public voice in decisions at the local level and, in this sense, launched an experiment in public participation in science policy.

This study assesses the success of that experiment based on a survey of biosafety committees in California and national data. We focus especially on public participation because this is the most innovative aspect of the regulatory system, as well as the most controversial. The findings suggest that lay members have played a constructive role on biosafety committees - although constrained in various ways - and that involvement has been generally worthwhile.

The time is ripe for such an assessment. In November, the Recombinant DNA Advisory Committee considered making all the NIH guidelines voluntary rather than mandatory, but instead left them mandatory while again reducing their scope and placing still more responsibility for monitoring on biosafety committees. (This recommendation was recently adopted by NIH.) Despite this expanding the only measure of confidence possible may be in the process by which decisions are made ${ }^{13}$. Thus, extraordinary effort has gone into developing a regulatory framework for recombinant DNA research that could provide sound, legitimate decisions responsive to local concerns; the Office of Technology report calls this framework "a possible model for societal decision-making on technological risks". The evidence presented in this paper points to certain strengths and weaknesses, but should not substitute for a more thorough investigation.

\section{Survey methods}

Data on Californian biosafety committees were obtained from surveys of chairpersons and nonaffiliated committee members. Questionnaires were sent to each chairperson of the twenty Californian committees registered in June 1980 with the Office of Recombinant DNA Activities of NIH. Nineteen committees responded, including twelve in academic institutions, five in non-profit research institutes and two in private corporations. Questionnaires were also sent to all of the 48 nonaffiliated committee members asking about committee performance and their own roles; forty-five questionnaires were returned, a response rate of 94 per cent. Due to these small sample sizes, few differences are statistically significant. Those that are significant are noted.

National data are based on a transcript of the plenary session of a meeting of about 200 biosafety committee chairpersons and other representatives, held in November $1980^{12}$; and on a brief survey completed by 
Average per cent of members on each committee (and range) who were:

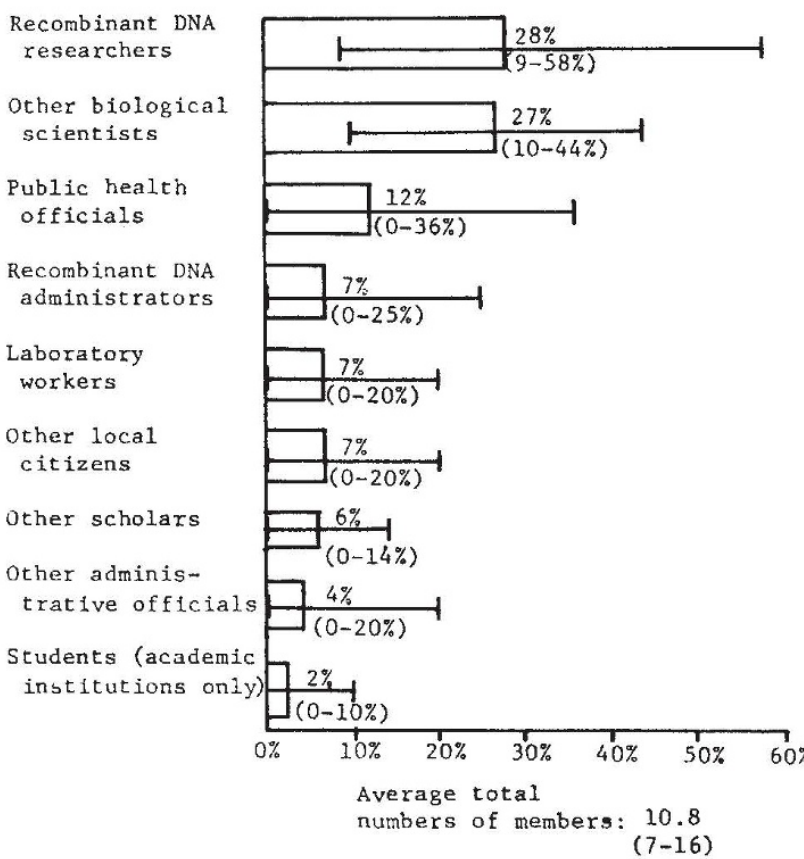

Recombinant DNA

ther biological

Public health

ficials

Recombinant DNA

administrators

Laboratory

ther scholars

ther adminis -

rative officials

$\frac{2 \%}{(0-10 \%}$

Average number of members (and range) on each committee Affiliated Nonaffiliated

\begin{tabular}{|c|c|}
\hline $\begin{array}{c}2.6 \\
(0-5)\end{array}$ & $\begin{array}{c}0.4 \\
(0-4)\end{array}$ \\
\hline $\begin{array}{c}2.7 \\
(0-5)\end{array}$ & $\begin{array}{c}0.2 \\
(0-1)\end{array}$ \\
\hline $\begin{array}{c}0.6 \\
(0-3)\end{array}$ & $\begin{array}{c}0.7 \\
(0-3)\end{array}$ \\
\hline $\begin{array}{c}0.7 \\
(0-2)\end{array}$ & 0 \\
\hline $\begin{array}{c}0.7 \\
(0-2)\end{array}$ & $\begin{array}{c}0.1 \\
(0-1)\end{array}$ \\
\hline 0 & $\begin{array}{c}0.8 \\
(0-3)\end{array}$ \\
\hline $\begin{array}{c}0.3 \\
(0-1)\end{array}$ & $\begin{array}{c}0.3 \\
(0-1)\end{array}$ \\
\hline $\begin{array}{c}0.3 \\
(0-1)\end{array}$ & $\begin{array}{c}0.1 \\
(0-1)\end{array}$ \\
\hline $\begin{array}{c}0.3 \\
(0-1)\end{array}$ & 0 \\
\hline $\begin{array}{l}8.2 \\
(4-13)\end{array}$ & $\begin{array}{c}2.6 \\
(2-4)\end{array}$ \\
\hline
\end{tabular}

Fig. 1 Membership of California biosafety committees.

98 of the 100 participants in the meeting's health surveillance workshop (survey results provided by $\mathrm{S}$. Barban, Office of Recombinant DNA Activities, NIH).

\section{Survey findings}

Since biosafety committees have had considerable discretion in interpreting guideline requirements, we describe first some general patterns of operation before discussing results on public participation.

Most striking is the great diversity in almost every aspect of committee activities from the frequency and content of meetings to the performance of mandated functions. For example, five of the Californian committees met once every three months during 1979, while several did not meet at all and one met fifteen times. Most of these meetings were convened as the need arose; in fact, eight of the nineteen committees reported no regularly scheduled meetings. About a third of the committees conducted some business by telephone or letter, several functioning this way almost entirely. Some committees delegated substantial authority to chairpersons; others relied heavily on subcommittees. Some committees were concerned only with recombinant DNA while others considered other potential biohazards.

The number of research proposals reviewed also varied greatly. Several California committees did not review any research proposals in 1979, while one reviewed 68 . In both the Californian and national samples, about 60 per cent of all biosafety cominittees reviewed ten or fewer proposals. Overall, committees spent about 30 minutes per proposal in meetings, but averages ranged from less than 10 minutes in one committee to more than an hour and a half in another. In general, smaller committees reviewed fewer proposals and spent more time on each of them. Some committees spent most of their time reviewing proposals while others concentrated largely on policy issues and other business. In California, committees at private corporations devoted the least time to policy and committee business ( 20 per cent), while those in academic institutions devoted the most time to such matters ( 57 per cent)

The guidelines require that institutions ensure "appropriate training" for biosafety committee members, principal investigators and laboratory staff; conduct "appropriate"' health surveillance of recombinant DNA research personnel; and adopt emergency plans for accidental spills $^{14}$. But since specific criteria are not provided, committees have interpreted these responsibilities quite differently. Nationally, the majority of committees offer no formal training courses. Training for committee members in Califoriia varied from none to a combination of university courses, manuals and laboratory tours. In the national sample, 89 per cent of the committees delegated responsibility for training laboratory staff to principal investigators, although several also assigned partial responsibility to the biological safety officer or to the biosafety committee.

Plans for emergency spills also differed considerably. Some Californian committees tailored plans specifically to recombinant DNA research, others relied on standard safety procedures. In the national survey, 13 per cent of the respondents reported that their biosafety committees had no emergency plans for serious accidents or contamination, and 51 per cent reported no such plans for workrelated illnesses. Although serious accidents in recombinant DNA laboratories were thought to be rare, more than a third of the respondents said that their committees would probably not know if any had occurred. About a third also said that laboratory staff were not told they were at increased risk of infection if pregnant or taking certain drugs. Overall, 15 per cent of the respondents reported that their committees did not do a "good job" in protecting the health and safety of laboratory personnel.

The majority of institutions had no special health surveillance for recombinant DNA laboratories. In California, 13 of the 19 committees reported no such surveillance, for reasons ranging from "lack of evidence of medical hazards" to the statement that "routine monitoring procedures are adequate". Likewise, fewer than half of the committees in the national survey had "established medical programmes". Most industrial biosafety committees reported that employees were given standard comprehensive medical examinations modified only slightly for recombinant DNA laboratory personnel. Participants differed as to what form local surveillance should take (routine physical examinations and serological sampling were generally not seen as useful), but they did agree that the present uncoordinated approach would not allow detection of low level health effects.

\section{Approval of research projects}

The Californian biosafety committees approved 96 per cent of research proposals reviewed in 1979, 73 per cent of them without modification. Only 4 per cent of all proposals were rejected, and the majority of committees (11 of 19) rejected none of the proposals considered.

There was again variation among committees. One, however, required modification of every proposal reviewed, while four approved all proposals without change. Rejection rates varied within a narrower range (0-10 per cent). The two corporate committees approved the largest proportion of proposals as submitted, compared with those in academic and research institutions ( 86 per cent versus 76 and 61 per cent); required the fewest modifications (14 versus 19 and 36 per cent); and had the lowest rejection rates ( 0 versus 5 and 3 per cent).

High approval rates could mean that only high quality proposals were submitted, that proposals had already been modified through informal consultation, or that the committee's review was not 
sufficiently critical. From the data to hand we cannot say which interpretation is most valid, although informal consultation appears to be common. Most local decisions were eventually confirmed by NIH; since 1978 the Office of Recombinant DNA Activities has rejected only an estimated 5 per cent of proposals approved by biosafety committees (statement of W. Gartland, Office of Recombinant DNA Activities, NIH, at 25 September 1980 meeting of the Recombinant DNA Advisory Committee).

Once proposals are approved, a number of committees apparently take no further formal responsibility for enforcing the guidelines. At the national meeting, about a third of the committees represented in one workshop did not monitor laboratory procedures after initial protocol approval. Yet, as the workshop leader pointed out, problems are more likely after equipment has been operating for a while. Because continuous monitoring is important, the guidelines include periodic review of experiments among the committees' mandated functions ${ }^{15}$. Evidently this requirement has been widely ignored.

\section{Composition of the committees}

The guidelines leave the choice of committee members to the institution, but require each committee to include at least two nonaffiliated "public" members, and to have a "biological safety officer" if research requiring $\mathrm{P} 3$ or $\mathrm{P} 4$ containment is being conducted $^{16}$. In California and elsewhere, most members are appointed by the administration. In Cambridge and Amherst, Massachusetts, the city governments are also involved in selection, but such external involvement is unusual. Most committees comply with the membership requirements, although the national survey revealed several institutions that had P3 facilities and no biological safety officer.

The Californian committees ranged in size from 7 to 16 members, averaging 11 , and all had the required number of nonaffiliated members. Figure 1 shows the average composition of these committees, and reveals wide variation. For example, recombinant DNA researchers comprised anywhere from 9 to 58 per cent of each committee, and there was comparable variability for most membership categories. The "typical" committee consisted of 55 per cent recombinant DNA and other biological scientists, with five to ten per cent of the membership in each of the other seven categories. Scientists were in the majority on most committees; only two contained fewer than 50 per cent scientists and one had more than 90 per cent. Six of the 19 committees were composed entirely of men, and all were chaired by men. Otherwise, there were few consistent patterns.

The guidelines state that the nonaffiliated members "shall represent the interest of the surrounding community with respect to health and protection of the environment", and they list as suitable examples "officials of State or local public health or environmental protection agencies, members of other local government bodies, or persons active in medical, occupational health, or environmental concerns in the community"' 17 Many of the Californian committees followed these suggestions: the two largest categories of nonaffiliated members were public health or other government officials ( 33 per cent) and local citizens ( 31 per cent).

The third major category reflects a rather different response: 25 per cent of all nonaffiliated members were recombinant DNA or other biological scientists working at different institutions. In two committees, the non-affiliated members consisted entirely of outside scientists. Although most such scientists were well qualified technically, their qualifications for representing community interests on public health or environmental issues were generally not evident from their curricula vitae.

A major premise underlying the proposals to broaden participation in biosafety committees was that local citizens and other non-scientists would raise different issues from scientists, offering contrasting perspectives. Data from the Californian survey support this premise. Predictably, lay nonaffiliated members had more trouble understanding discussions than did scientists ( 66 versus 43 per cent), and tended to rate their own contributions as less valuable. Several lay members reported that their suggestions were given little weight. One commented that "the committee served mainly as a rubber stamp ... The tasks require specialized expertise...".

On the other hand, lack of technical understanding could sometimes be advantageous. As one lay member said, it "requires the committee to think at a less hurried pace about potential problems ... to think through problems from a somewhat different perspective", and to seek "information that a trained person might have assumed was implicit". One said simply, "I am the gadfly."

Scientists and non-scientists also had different views about community influence. Lay nonaffiliated members were a good deal more sceptical than nonaffiliated scientists about direct

\begin{tabular}{|c|c|c|c|c|}
\hline & & Comm & tee size & \\
\hline & $7-10 n$ & mbers & $11-16 \mathrm{I}$ & embers \\
\hline & No & $1-3$ & No & $1-3$ \\
\hline Research proposal & local & local & local & local \\
\hline Approval rates & citizens & citizens & citizens & citizens \\
\hline Per cent approved as is & 70 & 63 & 98 & 81 \\
\hline Per cent approved with minor modification & 29 & 35 & 2 & 7 \\
\hline Per cent rejected & 1 & 3 & 0 & 11 \\
\hline Number of biosafety committees & 5 & 7 & 3 & 4 \\
\hline
\end{tabular}

community input to committee proceedings. Yet the nonaffiliated members, apparently because they viewed themselves as representatives of the community, were almost twice as likely as the scientists to say that committee decisions "always" took account of community views ( 38 versus 20 per cent).

\section{Value of public participation}

Committee representatives at the national meeting disagreed about the value of lay members. Some thought that such members contributed little. Others claimed that community members played an important role - that they helped to avoid potential conflicts of interest and "caused the committee to operate in a more tidy fashion". Several stressed the useful political function of public members in providing a sense of open communication with the community and in defusing potential animosity.

Do the benefits of public participation come at the cost of increased inefficiency or incompetent review? The Californian survery provides no evidence of such a tradeoff. Committees with local citizens reviewed almost twice as many research proposals in 1979 as those with no citizen members (20.4 versus 10.9 proposals), at the same time spending a somewhat larger fraction of meetings policy issues ( 36 versus 26 per cent) and covering more such issues (2.8 versus 2.5 per cent). Furthermore, although committees with citizen members spent less meeting time per proposal (27 versus 37 minutes), their review does not seem to have been more superficial than that of other committees, as they had a slightly higher rate of proposals rejected (6 versus 1 per cent) and of modifications requested ( 24 versus 21 per cent). These differences were independent of committee size, even though committees with citizen members tended to be larger, and larger committees tended to have lower approval rates. Within both smaller and larger committees (Table 1), those with citizen members had lower approval rates as well as higher rates of modification and rejection.

With lay members in the clear minority on most committees, it is perhaps surprising to find even small differences. These findings are consistent with psychological research indicating that lay people tend to define technical issues more broadly than experts and to be more Number of biosafety committees 
cautious in assessing possible risks ${ }^{18}$. And they bear out James Watson's warning that "public members . . . may take regulation seriously, unlike the molecular biologists"?

\section{Public access}

Community representation can also occur by direct participation in committee meetings. Thus, the guidelines "encourage" open meetings whenever possible ${ }^{19}$. Many commentators had urged stronger measures - mandatory open meetings that were publicized and held at convenient times - fearing that a voluntary provision would have little impact.

Such fears were justified. The Californian survey as well as the national meeting indicate that most committees have done little to encourage public participation; many have actively discouraged it. Almost half ( 42 per cent) of the Californian committees held no open meetings. Of the eleven committees that did have "public" meetings, only five held them on a regular schedule, in all cases on a weekday during working hours. More significantly, these meetings were apparently not announced. When queried about different forms of publicity, not one committee reported any announcement of meetings on bulletin boards, in campus or local newspapers or in other public media. At the national meeting, most chairpersons also reported that their committees did not publicize meetings widely. It is hardly surprising that public attendance has been minimal. About half of the Californian committees holding "public" meetings reported that no one attended while others had typical audiences of one or two.

As in 1978, many still dispute the value of open meetings. Almost half of the committee chairmen in California felt that open meetings were not desirable. Objections raised included the use of meetings as a "political" forum, possible violations of confidentiality, inhibition of frank discussions by committee members and fear that a lay audience ignorant of technical issues would impede the committee's operation.

In committees that had open meetings, however, almost all the chairmen thought they were desirable, for reasons ranging from preventing public misconceptions to informing committee members about community views. The performance of these committees compared favourably with those with closed meetings with regard to number of proposals reviewed and policy issues discussed (Table 2). And, like committees with public members, those with open meetings spent slightly less meeting time per proposal, yet were somewhat more critical in their judgements, rejecting more proposals as well as requiring more modifications. These differences were independent of both committee size and citizen representation. They suggest that open meetings do not make committees measurably less efficient and may, in fact, lead to a more critical review of proposals.

\section{Effects of open meetings}

If there are differences between open and closed meetings, they probably have less to do with specific issues raised by audience members than with subtle changes in atmosphere. Most people attending committee meetings asked general questions about research procedures or policies such as earthquake standards or laboratory safety. Yet comments from nonaffiliated members suggest that open meetings may nonetheless have had an effect on the committee. As one member noted, "community members are the only 'outsiders' at the meeting', adding, "Without them, who are the watchdogs?"

Assuming that open meetings facilitate direct communication with the community, one would expect committees with open meetings to receive more views from the community and to be more responsive. Table 2 shows just the opposite pattern. Nonaffiliated members on committees with open meetings more of ten said that the community had no input and that committee decisions did not always

Table 2 Selected comparisons of biosafety committees with open and closed meetings

\begin{tabular}{|c|c|c|}
\hline & \multicolumn{2}{|c|}{ Committees that have: } \\
\hline & $\begin{array}{l}\text { No } \\
\text { open } \\
\text { meetings }\end{array}$ & $\begin{array}{l}50-100 \% \\
\text { open } \\
\text { meetings }\end{array}$ \\
\hline \multicolumn{3}{|l|}{ Average number of research proposals } \\
\hline reviewed in 1979 & 14.1 & 18.0 \\
\hline Average meeting time spent per proposal (minutes) & 56 & 51 \\
\hline \multicolumn{3}{|l|}{ Proposal approval rates: } \\
\hline approved as is & $79 \%$ & $70 \%$ \\
\hline approved with modification & $20 \%$ & $24 \%$ \\
\hline rejected & $1 \%$ & $6 \%$ \\
\hline \multicolumn{3}{|l|}{ Average number of policy and procedural issues } \\
\hline discussed that were listed by chair & 1.6 & 3.5 \\
\hline \multicolumn{3}{|l|}{ Per cent of nonaffiliated members who said } \\
\hline $\begin{array}{l}\text { Per cent of nonaffiliated members who said } \\
\text { committee decisions did not always account } \\
\text { adequately for community views* }\end{array}$ & 47 & 78 \\
\hline Number of biosafety committees & 8 & 11 \\
\hline Total number of nonaffiliated members & 18 & 27 \\
\hline
\end{tabular}

$* P \ll 0.05$ adequately account for community views. One explanation may be that, as one member put it, open meetings "sensitize academic members to community concerns", leading to greater awareness of the ways in which the committee was not responding to the concerns they heard. Alternatively, members of committees with open meetings may simply have had higher expectations concerning community influence. Despite scepticism about the amount of community participation, however, almost all nonaffiliated members rated it as somewhat or very helpful.

Minutes of meetings provide another source of public information about committee proceedings. The guidelines require that such minutes and related documents be made available upon request ${ }^{20}$. Here again, this requirement has had a negligible impact; only one of the Californian committees reported receiving requests for minutes. Militating against such requests was the fact that the meetings were unannounced, and the minutes were typically stored in an administrative office not readily accessible.

There is a potential conflict between public accountability and the privacy necessary to protect trade secrets, as the guidelines acknowledge. So far, such conflicts have arisen mainly in proprietary institutions. At the national meeting, corporate committees reported that meetings were not open to the general public. Outside members, many paid by the companies, had to guarantee confidentiality, further limiting public accountability. In California, only the two corporate committees reported restricting the agendas of meetings because of proprietary concerns, although four other committees took special precautions to protect potentially patentable results before releasing minutes.

\section{Are biosafety committees worthwhile?}

Most chairpersons at the national meeting seemed to think that the time and effort spent by biosafety committees were greatly out of proportion to the risks of recombinant DNA research and therefore that the committees were largely unnecessary. Opinions expressed in the Californian survey were strikingly different. More than 80 per cent of the chairmen thought the guideline requirements concerning biosafety committees were "about right", while 91 per cent of the nonaffiliated members agreed that "biosafety committees as they presently function are worthwhile". This difference in views may be due not only to changes in perceptions of risk between 1979 and 1980 but also to the different sources of data - individual questionnaires versus the group process that produces a consensus.

Comments in the California survey, as in the national meeting, highlighted functions 
of biosafety committees. Many nonaffiliated members believed that the committees had an important role in promoting safety; for instance, one commented that they "force researchers to meet strict standards, as enforced by the campus environmental health officer. Several hazardous projects have either been aborted or redesigned because of our action'. Others thought that biosafety committees provided a useful forum for internal review of controversial issues and also "a sense of security to the public agency and to the scientific community no secrets, open communication'.

\section{Discussion}

In combining technical evaluation of scientific issues with provisions for accommodating social values and limiting conflicts of interest, institutional biosafety committees represent a significant policy innovation. The experience of the Californian committees - which appear to be typical of committees elsewhere suggests three general conclusions about their performance.

First, the considerable diversity of biosafety committees appears to reflect not only varying local circumstances but also variable effectiveness. Furthermore, the varying approaches (if any) to surveillance prevent development of a standardized system that might be more capable of establishing safety or detecting hazards.

Compliance has been variable even on specific requirements of the guidelines. Not all institutions conducting $\mathrm{P} 3$ research have appointed biosafety officers, and many do not monitor experiments after initial approval. Continuous monitoring is also hindered by infrequent committee meetings. The Office of Technology Assessment reports that biosafety committees "usually meet monthly", but only one of the 19 California committees met that often in 1979, and the frequency of meetings has undoubtedly declined since then. Stanford's committee, which met four times during 1979, now meets only once a year unless special problems arise (interview with D. Perkins, chairman of the Stanford Biosafety Committee by M. London).

The low rates of rejection of research proposals also raise questions about effectiveness. While these low rates may result from high quality proposals, they may also be due in some cases to inadequate review by the committee. Previous studies of similar institutional committees monitoring human subjects research, suggested that their low rate of rejection of proposed experiments was at least partly due to poor performance.

A second conclusion that may be drawn is that, given the highly decentralized nature of the biosafety committee system, clear minimum standards for essential elements of the system would be helpful. One of the key experimental variables in these committees has been public participation, yet the guidelines define this variable only very generally through the requirement for nonaffiliated members. The stated intent is that such members shall represent the surrounding community with respect to health and the environment; and the regulations stipulate that institutions are expected "to adhere to the purpose of the guidelines as well as to their specifics" 21 . But precisely how community interests are to be represented is left notably ambiguous, inviting disparate interpretations. Thus, a quarter of all nonaffiliated members were biological scientists from other institutions, many engaged in recombinant DNA work and with no evident qualifications for representing community interests.

More specific provisions concerning public representation, such as those recently adopted by the Food and Drug Administration for human subjects committees ${ }^{22}$, could have avoided this ambiguity. Provisions had been proposed in 1978 that committees include a certain proportion of non-scientists or reflect the demographic composition of the community, to ensure direct community involvement (following the examples in the guidelines) rather than representation by outside scientists ${ }^{11}$. But NIH rejected these proposals on the grounds that the biosafety committee "is in large part an expert committee whose essential function is to evaluate research protocols in respect to containment levels, using the explicit instructions of the guidelines. Rigid quotas are not necessary" ". With such ambivalence about the role of public members, it is not surprising that the regulations remained ambiguous.

It would also have been useful to define what constitutes "appropriate" training for biosafety committee members. Insufficient technical instruction compounded the frequent difficulty that many nonscientists had in understanding discussions, and a number stressed the need for more systematic training on basic research techniques and terminology.

\section{The role of the public}

Minimum standards for critical factors such as technical support and provisions for community representation need not restrict local experimentation in meeting or exceeding these baselines. Such standards are vital in a decentralized regulatory system where effectiveness depends largely on local structures and procedures. Without mechanisms for assuring accountability to community interests, public participation in biosafety committees has not been fully tested.

Yet it is clear that some committees did make a genuine effort to involve local citizens and were at least partially successful. The results of these experiences suggest a third conclusion which, although tentative, is perhaps the most important: given a chance, public participation seemed to work fairly well. Most community representatives took their role seriously and contributed to effective committee performance by broadening discussion and encouraging more critical scrutiny of research proposals. Public meetings, even with limited attendance also appeared to give committees a better understanding of community concerns without impeding committee operation. Many members believed that the committees were an important channel for public communication about an issue that remains sensitive, and that public involvement caused no evident harm to the research or to science.

Even if federal regulations are eliminated, the controversy over how to regulate recombinant DNA research is not likely to disappear. It has recently emerged anew in communities where genetic engineering companies have been set up. Because NIH regulations do not cover commercially-sponsored research, several towns and states have recently passed or drafted ordinances extending the present guidelines to industrial research and adding other requirements ${ }^{18}$. Thus, biosafety committees or their equivalent may well continue to be a key element in local regulation. As a workable mechanism for direct public participation, these committees have established a significant precedent in the decision process concerning science and technology.

We thank Drs William Gartland, Stanley Barban and Elizabeth Milewski of the Office of Recombinant DNA Research Activities, NIH, for making records available, Nancy Pfund and Ralph Silber for helping design and conduct the California survey, and Natalie Fisher, Valerie Herman and Kathy McFadden for technical assistance. Funding was provided under a grant from the NSF's EVIST Program and the National Endowment for the Humanities.

1. Impacts of Applied Genetics: Micro-Organisms, Plants and Animals (US Government Publications Office, Washington DC, 1981).

2. Thomasson, W. A. The Bulletin of the Atomic Scientists December, 26-32 (1979).

3. Wright, S. Environment November, 34-42 (1979). . Federal Register 43, No. 247 60108-60128 (1978).

5. Callahan, D. Hastings Center Report April, 20-23 (1977) 6. Wright, S. Environment May, 6 (1978).

7. Watson, J. D. The New Republic January, 12-15 (1979).

. Davis, B. D. Science 186, 309 (1974).

Wade, N. Science 197, 348 (1977).

10. Toulmin, S. New York Times, 12 March (1977).

11. Recombinant DNA Research Vol, 4, August-December 1978, Appendices (US DHEW, Publ. No. 49-1876, Government Printing Office, Washington DC, 1979).

12. Krause, R. M. Edited Transcript of Plenary Session III of the November 24-25, 1980 Institutional Biosafety Committee Chairpersons Meeting, 29 December (National Institute of Allergy and Infectious Diseases, NIH, 1980).

13. Bazelon, D. Science 205, 277-280, July (1979).

14. Sections IV-D-1-g, IV-D-1-h, and IV-D-3-d, respectively.

14. Sections IV-D-1-g,
15. Section IV-D-3-c.

16. Section IV-D-4.

17. Section IV-D-2-a.

18. Fischoff, B., Slovic, P. \& Lichtenstein, S. in Progress in Resource Management and Environment Planning Vol. 3 (eds O'Riordan, T. \& Turner, R. K.) (Wiley, New York, in the press).

19. Section IV-D-2-g.

20. Section IV-D-2-h.

21. Section IV-A.

22. Fed. Register 46, No. 17, 8977, Part IX, pgh. 56, 107 (c), January 27 (1981). 